\title{
Valorização do Magistério ou Darwinismo Profissional?
}

\author{
Maria Angélica Pedra Minhoto* \\ Marieta Gouvêa de Oliveira Penna**
}

\section{Resumo}

A insatisfação em relação ao desempenho da educação básica é grande, e as avaliações de monitoramento persistem indicando lacunas nos sistemas de ensino. Em resposta, a Secretaria de Educação de São Paulo propôs medidas de incentivos financeiros ao magistério paulista. Além do bônus por desempenho, foi enviado à Assembléia Legislativa um Projeto de Lei Complementar (PLC) que institui o sistema de promoção por mérito. Este artigo discute os limites do principio de eficiência do PLC, tendo em vista assentar-se na correlação entre aumento da remuneração e melhoria de desempenho.Analisa também os limites do conceito de qualidade educacional atrelado à lógica de mercado. São apresentados preceitos e incongruências do PLC, resultados de trabalhos internacionais que testaram a eficiência de políticas de remuneração por mérito e, finalmente, são tecidas considerações em relação ao PLC, tendo em vista a experiência internacional.

Palavras-chave: Magistério. Carreira. Remuneração.

\section{Teaching valorization or professional Darwinism? \\ Abstract}

The dissatisfaction about the results of basic education performance in Brazil is high, and the National Assessment of Education still indicates a persistent gap in the area. In response to this fact, the Department of Education of São Paulo State has proposed measures to encourage its teachers financially. In addition to the performance bonuses, already in force, a system based on the promotion by

* Doutora em Educação, Pontifícia Universidade Católica de São Paulo (PUC-SP); Professora de Política e Organização da Educação Básica (POEB), Universidade Federal de São Paulo (UNIFESP).

E-mail: mminhoto@unifesp.br

** Doutora em Educação (PUC-SP); Professora de Metodologia da Pesquisa em Educação, UNIFESP. E-mail: marieta.penna@yahoo.com.br 
merit within the teaching career was sent to the Legislative Assembly as a Supplementary Bill (PLC). This article dicusses the limits of the principles and the efficiency of PLC, based on the positive correlation between increase in compensation and performance improvement. It also analyzes the limits of the concept of quality education coupled with the logic of market. We present the precepts and inconsistencies of the PLC, the results of international studies related to the effectiveness of policies for merit pay, and finally we make some considerations about the $P L C$, in view of the international experience.

Keywords: Teaching. Career. Merit pay.

\section{¿Valoración del magisterio o darwinismo profesional? \\ Resumen}

Existe mucha insatisfacción con respecto al desempeño de la educación básica en Brasil, y, por otro lado, las evaluaciones de monitoreo continúan señalando vacios en los sistemas de educación. Como respuesta, la Dirección General de Escuelas del Estado de San Pablo ha propuesto medidas para apoyar financieramente a sus maestros. Además de las primas por rendimiento, ya en vigor, se envió a la Asamblea Legislativa un Proyecto de Ley Complementaria (PLC) que establece un sistema de promoción por méritos a la carrera docente. Este artículo aborda los límites del principio de eficiencia del PLC, basado en la correlación entre el aumento de las remuneraciones y la mejora del rendimiento, también aborda los límites del concepto de calidad de la educación asociado a la lógica del mercado. Se presentan los preceptos y las discrepancias del PLC, resultados de estudios internacionales sobre la eficacia de las políticas de remuneración por mérito y, finalmente, se hacen algunas consideraciones sobre el PLC, en vista de la experiencia internacional. Palabras clave: Magisterio. Carrera. Remuneración.

\section{Introdução}

A insatisfação em relação ao desempenho dos estudantes da rede pública de educação básica no Brasil é grande, e a impressão que se tem é a de que não para de aumentar. Comparações internacionais feitas por meio de testes padronizados, tal como as diversas edições do Programa Internacional de Avaliação de Alunos (PISA), amplamente divulgadas pela mídia, colocam o pais entre as nações que apresentam os niveis mais baixos nas escalas de proficiência em Letramento, ou Habilidade de Leitura, Matemática e Ciências, mesmo quando considerados apenas os alunos de classe social e faixa econômica elevadas (FRANCO, 2002). Em âmbito nacional, as avaliações externas às escolas, como o Sistema de Avaliação da Educação Básica (SAEB), a Prova Brasil, o Sistema de Avaliação do Rendimento Escolar do Estado de São Paulo (SARESP), entre outras, persistem indicando lacunas consideráveis no desempenho dos sistemas de ensino. 
Em resposta ao pifio resultado da rede escolar paulista, nos últimos anos, e à pressão da opinião pública, os atuais gestores da Secretaria de Estado da Educação de São Paulo (SEESP) propuseram novas medidas baseadas em incentivos financeiros aos integrantes do Quadro do Magistério, com o objetivo de turbinar a qualidade da educação básica. Em março de 2009, os professores e demais funcionários da SEESP receberam bônus por desempenho em razão dos resultados alcançados pelas escolas da rede, por meio de um indicador chamado Índice de Desenvolvimento da Educação do Estado de São Paulo (IDESP)'. Em 6 de agosto desse mesmo ano, o atual Secretário da Educação enviou à Assembléia Legislativa do Estado o Projeto de Lei Complementar $n^{\circ}$. 29/09 ( $P L C n^{\circ} 29 / 09$ ) que tem como objetivo instituir um sistema de promoção por mérito para os integrantes do magistério estadual, reformulando o plano de carreira da categoria ${ }^{2}$.

Tal Projeto de Lei se insere em debate internacional sobre a melhoria da educação, em que o professor é visto como peça-chave no processo de implementação de reformas educacionais. A questão da qualidade do ensino, nos termos dessas reformas, passa pela melhoria das condições de trabalho do professor e por seu reconhecimento como profissional, com ênfase no desenvolvimento de políticas eficientes com foco na formação e na carreira docentes.

0 presente texto tem por objetivo discutir os limites do princípio de eficiência, projetado em futura Lei (SÃO PAULO, 2009b), ao assentar-se na convicção de que existe correlação significativa entre o aumento da remuneração do magistério e 0 crescimento no nivel de desempenho dos alunos. Além disso, pretende discutir os limites do conceito de qualidade de ensino quando atrelado à lógica da concorrência de mercado, tal como se afigura no PLC em questão.

Para tanto, esta exposição se organiza em três partes. Inicialmente são apresentados, em linhas gerais, os preceitos e algumas incongruências contidas no PLC; em seguida, são discutidos resultados obtidos em trabalhos internacionais que buscaram testar a eficiência de políticas educacionais voltadas à remuneração por mérito, com o objetivo de iluminar o debate nacional a partir de experiências existentes; e, por fim, são tecidas algumas considerações finais em relação ao projeto de lei, tendo em vista a experiência internacional.

10 IDESP é um indicador composto que, a exemplo do IDEB (Índice de Desenvolvimento da Educação Básica do Ministério da Educação (MEC), pretende traduzir a qualidade da educação paulista a partir de dois outros índices: o desempenho dos alunos no SARESP e o fluxo escolar.

20 PLC $n^{\circ}$ 29/09 foi transformado na Lei Complementar $n^{\circ} 1097$ (SÃO PAULO, 2009b), instituindo o sistema de promoção para os integrantes do quadro do magistério da SEESP. A referida lei complementar foi regulamentada pelo Decreto $\mathrm{n}^{0} 55.217$ (SÃo PAULO, 2009a). 


\section{Projeto de Lei Complementar no 29/09: um passo na direção da valorização da carreira do magistério e da melhoria da qualidade da educação paulista?}

A exposição de motivos do PLC, assinada pelo atual Secretário Estadual de Educação de São Paulo, o Sr. Paulo Renato Costa Souza, deixa explícito o objetivo de valorizar os servidores do magistério pela remuneração por mérito. A proposta prevê que a promoção dos profissionais poderá ocorrer em uma escala de cinco faixas de elevação para cada classe de professor, para diretores e para supervisores, além das evoluções por níveis previstas na atual legislação.

Só é facultado ascender a uma faixa superior aos profissionais do Quadro do Magistério oficial em efetivo exercício de suas funções e que se submeterem a uma avaliação de conhecimentos, em processo que poderá ter caráter teórico, prático, ou mesmo teórico e prático. Essa avaliação deverá ocorrer anualmente, sob a responsabilidade da Escola de Formação de Professores de São Paulo ${ }^{3}$.

A realização de uma avaliação de conhecimentos específicos ao exercício docente, por um órgão da administração pública, não é medida simples e necessita ser problematizada! Para dizer o mínimo, tal iniciativa deveria ser amplamente debatida, tendo em vista que contempla determinada concepção de professor que deverá atuar nas escolas públicas estaduais, tornada explícita por meio da definição de conhecimentos considerados necessários ao exercício dessa função. Ao analisar processos formativos direcionados aos professores, Azanha (2006) destaca o caráter prescritivo e salvacionista neles implicados, nos quais novas propostas metodológicas são apresentadas em tom de convencimento e com o suposto de trazerem a solução para os problemas relacionados ao ensino. Na atualidade, aponta ainda a tentativa de hegemonia do discurso construtivista. Tais constatações contribuem para reafirmar a necessidade de ampliar o debate em torno da "inevitabilidade" dessa nova avaliação, bem como de seus parâmetros.

Para participar do primeiro processo de avaliação e ascender à faixa 2, o PLC prevê que os servidores tenham quatro anos de efetivo exercício no cargo, o que vale também para os temporários, estabilizados pela Lei Complementar n 1.010 , de $1^{\circ}$ de julho de 2007. Em cada processo de promoção será permitido avançar apenas uma faixa e, para concorrer à faixa subsequente, o profissional deverá permanecer no mínimo por três anos em sua posição. Esse tempo só será computado se estiver em efetivo exercício de sua função e será contado do ingresso no cargo (faixa 1) até a última elevação, havendo interrupção da contagem quando houver afastamentos, licenças de saúde e licenças para o tratamento de familiares.

3 A Escola de Formação de Professores do Estado de São Paulo foi criada para fornecer treinamento adicional aos novos profissionais da rede pública de ensino. Além de aprovados em concurso público, professores, diretores e supervisores de ensino deverão realizar 360 horas de atividades, durante quatro meses, e precisarão de aprovação no curso para se efetivarem. 
Além disso, para participar da prova, é necessário que o professor permaneça na escola por $80 \%$ do interstício e some $80 \%$ do máximo de pontos da tabela de frequência. Os critérios para a elaboração de tal tabela serão fixados por decreto, sendo que os professores mais bem pontuados serão os que não utilizarem qualquer espécie de abono. Segundo observações do Sindicato dos Professores do Ensino Oficial do Estado de São Paulo (APEOESP) (CAMPANHA..., 2009), a exigência incondicional de alto índice de frequência não respeita direitos estabelecidos pela legislação, tais como o abono de faltas médicas, já restritas pela Lei no. 1.041 (SÃO PAUL0, 2008); a licença-prêmio e outras. Serão penalizados no processo de evolução os professores que tenham feito uso desse tipo de faltas. Vale ressaltar que é significativo o problema do absenteísmo na rede estadual de ensino de São Paulo e que requer medidas preventivas, como mostra o trabalho de Gesqui (2008), mas não se pode simplesmente desconsiderar direitos que foram devidamente adquiridos pela categoria.

0 PLC estipula que será beneficiado, em cada processo de promoção, o limite máximo de $20 \%$ de servidores integrantes de cada uma das faixas, ainda que um número maior de profissionais tenha se saído bem no processo avaliativo. A justificativa do Secretário para 0 estabelecimento de tal fronteira baseia-se no critério da "disponibilidade orçamentária", 0 que retrata o constrangimento e a subordinação das políticas que pretendem valorizar 0 magistério a padrões alheios às necessidades intrínsecas ao fomento da qualidade em educação. A esse respeito, a APEOESP (CAMPANHA..., 2009) chama atenção para o fato de o PLC estabelecer o número máximo de promoções a serem concedidas, mas não fixar um número mínimo, deixando exclusivamente a critério do governo essa fixação, o que, em determinadas situações, poderá ser um número próximo de zero.

Cabe, também destacar que um tipo de promoção como esse tende a incentivar uma busca individualizada por treinamento, podendo refletir no próprio exercício da função ao estimular a competitividade e não a solidariedade entre os profissionais. Além disso, parece responsabilizar os professores por sua própria formação, tornando-a, praticamente, um dever. A tão propalada troca de experiências, necessária à valorização das boas práticas e ao desenvolvimento de trabalhos coletivos na escola, certamente será prejudicada.

Outro ponto para o qual a APEOESP (CAMPANHA..., 2009) chama atenção é o fato de o Governo ter enviado o PLC à Assembleia Legislativa sem antes chamar as entidades representativas do magistério para informá-las sobre o teor da proposta. Isso desrespeita a Lei Complementar no 836 (SÃO PAULO, 1997), que cria comissão paritária para discutir previamente quaisquer assuntos relativos à carreira do Magistério - sobretudo os referentes à evolução funcional.

Ainda em relação às promoções entre as faixas, note-se que o sistema estabelecido é restritivo e hierárquico, na medida em que exige dos profissionais notas mínimas nos exames e estabelece diferentes percentuais de aumento em relação ao vencimento inicial: para a promoção entre as faixas 1 e 2, a nota na prova deve ser no mínimo 6 , e 0 
percentual de aumento sobre o vencimento inicial é de 25\%; da faixa 2 para a 3, a nota mínima deve ser 7, e o aumento sobre o vencimento inicial é de 50\%; da faixa 3 para a 4, a nota é no mínimo 8, e o aumento sobre o vencimento inicial é de 75\%; e da faixa 4 para a 5, a nota deve ser no mínimo 9, e o aumento sobre o vencimento inicial é de 100\%.

Os critérios para a classificação final dos profissionais são: 1) apresentar maior pontuação no processo avaliativo; 2) ter maior tempo de permanência na unidade de ensino ou administrativa de classificação, considerada a faixa em que concorrer à promoção; e 3) apresentar maior pontuação na tabela de frequência. De acordo com o PLC, as consequências esperadas em decorrência da implantação do sistema de promoção serão: a possibilidade de ganhos em função de esforço e dedicação pessoal (valorização do mérito); tornar a carreira do magistério mais atrativa; estimular o aperfeiçoamento individual; permitir à SEESP direcionar o aperfeiçoamento para áreas onde as deficiências forem notórias; melhorar a gestão escolar tendo em vista o foco no resultado escolar; e melhorar a aprendizagem, em decorrência de professores preparados e gestão eficiente.

Propostas similares à do PLC não se afiguram como novidade em diversos países do mundo. Políticas que associam, explicitamente, os diferenciais de salários à performance profissional, compreendendo que há uma relação imediata entre incentivos monetários e motivação dos professores para melhorarem a qualidade de seu trabalho, encontram cada vez mais espaço em paises centrais, como os EUA e a Inglaterra, e nações africanas e latino-americanas, como Togo, Chile e México, mesmo sem evidências empíricas da validade dessa relação. A seguir, apresenta-se quadro contextual em que é possivel compreender a proposta do PLC, bem como alguns resultados obtidos em trabalhos internacionais que buscam testar a eficiência dessas políticas, com o objetivo de iluminar o debate nacional.

\section{Contextualizando o PLC: algumas reformas internacionais}

0 novo sistema de promoção para os integrantes do Quadro do Magistério da SEESP, tal como disposto no PLC, deve ser compreendido relacionado a um conjunto de reformas educacionais na atualidade, que visam a promover a qualidade na educação e nas quais os professores são vistos como protagonistas. Um dos aspectos relevantes para que ocorra o envolvimento dos professores com a implementação e o sucesso das reformas é a melhoria de suas condições de trabalho e, entre elas, está a promoção de incentivos relacionados à carreira docente, estabelecidos em conjunto com estratégias de controle e avaliação de seu desempenho profissional. Trata-se de regular o trabalho do professor para que "funcione" como principal protagonista das reformas.

Na síntese das recomendações estabelecidas pela Conferência Regional "0 desempenho dos professores na América Latina e no Caribe: novas prioridades", realizada em Brasília, em julho de 2002 (CAREAGA, 2004), são apontadas questões relacionadas à formação, condições de trabalho e carreira docentes, que expressam a lógica que 
aqui se quer destacar. No que diz respeito à carreira do professor, as recomendações vão ao sentido de criar incentivos para seu desenvolvimento, atrelados ao implemento de mecanismos de controle e avaliação da formação e do desempenho profissionais, que apóiem uma educação de qualidade, por meio da qualificação do professor.

Discutir a lógica implicada na ideia de qualidade do professor é imprescindivel, visto estar impregnada por questões relacionadas à meritocracia, ao individualismo e ao controle dos processos educacionais sob novas bases. As revisões na regulamentação da carreira docente, constantes na atualidade, evidenciam a forma como as políticas de valorização do magistério têm ocorrido nos últimos tempos. Postulam a necessidade de se "premiar" o professor pelo desempenho eficiente e por sua formação ou capacitação para o exercício profissional e, ao mesmo tempo, introduzem mecanismos de controle de qualidade em relação à formação. Para Aguerrondo (2004), trata-se de modernizar a intervenção estatal e garantir a qualidade do professor e a melhoria de seu desempenho profissional, estabelecendo, num primeiro momento, um controle sobre a formação inicial, a fim de verificar se propicia as competências exigidas para o desempenho da função docente.

Se, de fato, esse controle é necessário, importa analisar criticamente a maneira como a formação tem sido compreendida na atualidade, centrada na ideia de competências mais que na aquisição de saberes e conhecimentos necessários ao exercício profissional, assumindo caráter técnico e instrumental (FREITAS, 2002). Além disso, o conceito de competência voltado ao ensino para o mundo "pós-revolução tecnológica", em constante transformação, aliado à ideia da eficácia dos sistemas educacionais, introduz a necessidade de permanente checagem do desenvolvimento dos professores, uma vez que as competências devem se desenvolver ao longo da trajetória profissional. Nesse sentido, Bourdieu (1998), ao discutir as relações de trabalho estabelecidas na atualidade, destaca a sensação de profunda insegurança e incerteza dos trabalhadores em decorrência do estabelecimento de uma ordem social fundada em competências, que os obriga a atenção e reinvenção permanentes.

Como visto, uma das maneiras de cálculo do êxito dos processos de ensino tem sido a mensuração do conjunto de competências do professor no sentido de assegurar 0 desenvolvimento da atividade escolar. Para se premiar a eficiência, é preciso, portanto, controlar as instituições de formação e avaliar os professores ao longo de sua carreira profissional, com o estabelecimento de checagens periódicas dessas competências.

Segundo Aguerrondo (2004), é fundamental o controle da competência profissional, pois permite colocar em xeque a estabilidade docente, que historicamente desconsidera 0 desempenho profissional. Para o autor, trata-se de contrapor os direitos individuais do servidor público aos direitos da população por uma educação de qualidade, revendo-se critérios para o ingresso, ascensão e permanência na carreira. Segundo essa lógica, o sistema de promoções, baseado na antiguidade, não valoriza o bom desempenho profissional. Remunera-se igual, independente dos esforços e dos resultados obtidos. 
Nesse sentido, os novos sistemas de regulamentação da carreira docente têm se prestado a controlar o trabalho do professor e impor um padrão de qualidade e desempenho, inclusive condicionando a permanência profissional a processos externos de avaliação. Os aspectos centrais avaliados nesses processos têm recaído sobre a eficácia técnica, a escolha de métodos e instrumentos e a forma correta e eficiente de se estabelecer cruzamentos de dados para garantir eficácia nos processos de gestão e planificação. Avaliar a qualidade do trabalho docente se coloca como mecanismo de comunicação de normas organizadoras e profissionais. Sua importância pode ser inferida a partir da criação do "Grupo de Interesse" para estudar e aprofundar o tema da Avaliação Docente, estabelecido na $X$ Reunião de Coordenadores Nacionais do Laboratório Latino-Americano de Avaliação da Qualidade da Educação. Seu objetivo explícito é o "de produzir insumos informativos que sirvam de guia para a tomada de decisões a respeito dessa política educacional nos paises da região" (SCHULMEYER, 2004, p. 257). A avaliação docente se estabelece como política educacional, uma vez que o desempenho profissional do professor é visto como "muito influente" para o salto qualitativo na gestão escolar, visando à qualidade do ensino. Nessa lógica, 0 êxito ou o fracasso do ensino dependem do professor.

Trata-se de, por um lado, promover o desempenho docente por meio da premiação dos "melhores" avaliados, instaurando a meritocracia e a competitividade, ou seja, fomentar e favorecer o aperfeiçoamento do professorado, controlando e estimulando sua formação, a fim de promover o uso racional e eficiente dos recursos humanos disponiveis. Por outro, trata-se da instaurar uma cultura de avaliação do desempenho e da eficácia da gestão. 0 incentivo ao desempenho docente se estabelece como forma de promover os melhores, tornando a carreira mais atrativa. De acordo com Mizala e Romaguera (2004), esse incentivo pode ocorrer por meio da adoção de diferentes estratégias de premiação ou estabelecimento de diferenças salariais, tais como: premiação pelo mérito individual; por competências certificadas; pela promoção na carreira; e pela premiação de estabelecimentos escolares.

Nos Estados Unidos, iniciativas de premiação individual de professores são antigas, datam dos anos 1920, passando por uma onda nos anos 1950 e, mais recentemente, nos anos 1980. As reformas educacionais da década de 1980 tiveram por base os resultados de diversos levantamentos - o mais destacado deles intitulado $A$ Nation at Risk. Esses relatórios produziram o consenso de que modificar o pagamento dos professores seria central para a melhoria da escola, principalmente no que toca à remuneração inicial, tendo em vista a possibilidade de aumentar o status e a atratividade da carreira em relação a outras profissões.

Nos Estados Unidos, o pagamento por mérito pode ser considerado, hoje, um adicional à estrutura da carreira e não o principal fator que define o salário final dos professores. A dificuldade em identificar e medir o mérito da performance docente e relacioná-la à promoção dos alunos, que geralmente é fruto de trabalho em equipe, foi decisiva para desestimular a utilização desse mecanismo de remuneração naquele pais. Além disso, vários estudos têm apontado pouca evidência empírica da 
influência da remuneração baseada no mérito dos professores e a melhora no desempenho dos alunos (EBERTS; HOLLENBECK; STONE, 2000; REICHARDT, 2001).

Outra pesquisa norte-americana sobre o tema, conduzida entre 1993 e 1994, com dados provenientes de estudos de caso e de dois instrumentos de avaliação de políticas educacionais - dados da Avaliação Nacional do Progresso Escolar, State National Assessment of Educational Progress (NAEP), e do Levantamento sobre as Escolas e seu Funcionamento, School and Staffing Survey (SASS) -, analisa como a qualificação dos professores e outros insumos da escola se relacionam ao desempenho dos alunos (DARLING-HAMMOND, 2000). As conclusões do estudo, feito em 50 estados norte-americanos, sugerem que os investimentos em qualificação dos professores apresentam de longe a mais forte correlação com o desempenho dos alunos em leitura e matemática, principalmente tendo em vista o resultado das análises quantitativas que controlaram variáveis como o nivel socioeconômico dos estudantes e o status linguistico. Com dados agregados, as variáveis de qualificação dos professores aparecem mais fortemente relacionadas à realização dos estudantes do que propriamente aspectos como o tamanho das turmas, os niveis de despesa global das instituições e os salários dos professores. Além disso, a análise qualitativa sugeriu que as políticas adotadas em matéria de formação, certificação, contratação e desenvolvimento profissional de professores produzem diferenças significativas para qualificar e capacitar o trabalho docente.

Em geral, os critérios mais significativos de performance já estão previstos nos planos de carreira como fatores de evolução funcional: são anos de experiência e formação educacional; jornada de trabalho; comprometimento com a profissão, tal como a localização da escola, o número de alunos atendidos, o indice de periculosidade do local, 0 investimento no crescimento acadêmico, entre outros. Nos EUA, quanto mais subjetivos os critérios de ascensão na carreira, maior é a dificuldade em estabilizar um plano para o magistério. Ao mesmo tempo, quanto maior a diferenciação interna da carreira e as responsabilidades dos professores nos planos, mais aceitáveis se tornam e com maior chance de sucesso entre os professores (JACOBSON, 1992, p. 50).

Ainda de acordo com Jacobson (1992), evidências mostram que o professor sentese mais estimulado pelos conteúdos e processos de trabalho do que pelas oportunidades de ganho extra. Em seu estudo, não foi possível encontrar relação imediata entre estímulo (pagamento por mérito) e resposta (mudança de comportamento do professor), pois, além da complexidade da relação do professor com o seu trabalho, tem sido difícil estabelecer critérios que definam, com precisão, um bom professor, devido à natureza complexa da docência. Mesmo que vantagens salariais tivessem efeito imediato na performance do professor, o autor reitera o problema de mensurá-la, já que o "produto" da docência é também complexo, impreciso e, portanto, de dificil classificação.

Kelley e Odden (1995), por sua vez, atribuem o insucesso dos esforços oficiais feitos nos EUA para modificar a forma de remuneração dos docentes, na década de 1980, à falta 
de nexo das propostas com as reais necessidades organizacionais e os processos de trabaIho das escolas. Afirmam que, em boa parte dos Estados norte-americanos, a competição entre professores tornou-se inerente à remuneração por mérito individual, na medida em que os docentes passaram a disputar recursos limitados, o que acabou se colocando na contramão da cultura colaborativa típica da maioria das escolas de alto desempenho.

Para os autores, além de não ser possível definir um plano de carreira ideal ou universal para todos os professores, a ideia de estabelecer tão somente um sistema de compensação não se estabelece como solução eficiente para alcançar os objetivos educacionais e superar o baixo desempenho de alunos. Apesar disso, reconhecem que sistemas de compensação são ferramentas com potencial para apoiar as iniciativas contidas em reformas educacionais, para recompensar a excelência e fomentar um clima educacional de qualidade.

No Reino Unido, desde o ano de 2000, foi instituída para professores a remuneração relacionada a desempenho: Performance Related Pay (PRP), como parte de uma unidade política que visava à melhoria dos resultados do serviço público de ensino, porém por sua abrangência se constituiu mais como um aumento salarial geral para os professores (BURGESS et. al., 2001). Quando atingem o topo da carreira, estruturada em uma escala simples de nove faixas, os professores tornam-se elegiveis ao esquema de pagamento por performance. São, então, avaliados em diferentes categorias, incluindo o desenvolvimento profissional e o sucesso escolar dos alunos. Se forem bem sucedidos, recebem um bônus anual de $€ 2.000$ (duas mil libras, ou cerca de $R \$ 6.000,00$ ), que continuarão a receber até ao final de sua carreira, sem a necessidade de serem reavaliados. Além disso, as escolas britânicas passam por testes anuais e a elas são pagos prêmios de acordo com seus resultados em duas categorias: para as que têm melhorado ao longo do tempo e para as que se destacam. Os prêmios são distribuidos entre os professores como bônus.

Já, de acordo com Burgess e outros (2001), o esquema de pagamento por performance não foi concebido para motivar os professores, mas para aumentar o salário de alguns sem alterar a média. Os resultados da pesquisa mostram que essa concepção não gera melhor desempenho do ensino, pois os professores não são motivados por recompensas extrínsecas, mas pelo altruísmo, pelo reconhecimento da escola onde atuam, pelo reconhecimento de seus pares e por crescimento pessoal.

De acordo com os autores, os problemas do pagamento por desempenho individual giram em torno de três questões que se sobrepõem: primeiro, o ensino é multidimensional, visando a resultados muito mais amplos do que resultados de exames ou testes; em segundo lugar, o ensino envolve o trabalho em equipe, incompativel com um regime individual; finalmente, sendo profissionais, os professores não necessitam de incentivos financeiros para induzir maiores esforços e comprometimento com a educação de seus alunos.

Os resultados de outro estudo inglês, com 1.000 professores em topo de carreira que têm como função aplicar um exame que qualifica a performance e aumenta a 
remuneração de professores em início e meio de carreira, Threshold Assessment, mostram que $75 \%$ deles não entendem o exame como uma boa ferramenta de indução das ações ou modos de ensinar dos professores em sala de aula. Entre eles, $60 \%$ se opõem ao pagamento por mérito e $39 \%$ são favoráveis, apesar de manifestarem descontentamento com o modo como a política foi colocada em prática ( WRAGG et al., 2003).

Entre as pesquisas que se debruçam em experiências desenvolvidas em paises periféricos, Vegas e De Laat (2003) usando dados do Togo afirmam que alunos de professores regulares têm desempenho superior ao de professores temporários, mesmo após terem sido controladas variáveis como condição familiar, características da escola e da sala de aula. Para os pesquisadores, a variação nos métodos de ensino, o absentismo e o desgosto a respeito dos pagamentos distintos entre os dois tipos de contrato não são suficientes para explicar as diferenças de desempenho dos alunos. Em vez disso, os resultados sugerem que as reformas efetuadas naquele país produziram uma redução na contratação de professores iniciantes de alta qualidade.

Motivados por pressões orçamentárias, paises do Oeste Africano têm adotado iniciativas políticas de reduzir salários e benefícios de professores novos. 0 Togo é um dos paises que adotou a política de contratação de professores temporários, sem estabilidade e que recebem menores salários e beneficios que os professores regulares. De acordo com os pesquisadores, o impacto dessa iniciativa na realização do estudante é negativo e se deve principalmente ao declínio na qualidade dos que optam por entrar na carreira. Ao invés da retórica de valorização profissional, o que se percebe naquele pais é a investida na desprofissionalização do docente.

Já no México, para a progressão na carreira, são levados em consideração aspectos como formação, experiência, capacitação em serviço e desempenho no trabalho, para o que são realizadas provas com os professores e com os alunos, de acordo com Rama e Navarro (2004). Além disso, todos os professores têm a possibilidade de ascender na carreira.

No que toca ao incentivo a estabelecimentos escolares, Mizala e Romaguera (2004) descrevem a experiência chilena, a fim de melhorar o desempenho dos alunos e diminuir a evasão e a repetência. No Chile, são oferecidos incentivos aos estabelecimentos escolares cujo desempenho for avaliado como de excelência. Uma parte dos recursos vai diretamente aos professores e outra vai para o estabelecimento. 0 objetivo dessa politica de incentivos é identificar os bons e os maus colégios, os bons e os maus professores, gerar indicadores de qualidade e tornar transparentes os resultados educacionais.

No estado de São Paulo, a modalidade de remuneração por bônus, instituída em março deste ano, estabeleceu que quanto mais próximas as escolas chegassem da meta do IDESP maiores seriam os bônus de seus funcionários. Se a meta da escola para 2008 fosse alcançada em 100\%, os funcionários receberiam bônus 
integral, ou 20\% da soma dos 12 salários mensais, perfazendo um total de 2,4 salários mensais a mais. Se as escolas alcançassem $50 \%$ da meta, os funcionários receberiam 1,2 salários mensais a mais. Mas, se a escola superasse a meta em $20 \%$, os servidores receberiam $120 \%$ do bônus, chegando ao valor máximo pago igual a 2,9 salários a mais. Além disso, para receberem integralmente o valor do bônus, os professores deveriam ter cumprido toda a sua carga horária - se, por exemplo, tivessem cumprido $50 \%$ de sua carga, eles receberiam a metade do bônus de sua escola. No PLC, fica mantido o atual sistema de pagamento de bônus por resultado em função do desempenho das escolas.

Embora os educadores, economistas, gestores e o público em geral acreditem que os professores são o elemento fundamental na educação, a relação entre as características do professor - incluindo salários - e os resultados dos alunos tem sido difícil de ser estabelecida empiricamente, como visto nas pesquisas conduzidas em diferentes locais. Além disso, a questão mais importante e que permanece sem resposta é a de como atrair professores, motivá-los e retê-los na profissão.

De acordo com Rama e Navarro (2004), as políticas para a definição da carreira docente deveriam atentar para o controle sobre a titulação, os exames de ingresso, a realização de avaliação periódica, capacitação permanente e controle sobre a frequência. Destacam o desenvolvimento da carreira por escalões de acesso, a fim de atrair e reter bons profissionais, por meio da oferta de incentivos para que seu desempenho seja constantemente melhorado. São estabelecidos diferentes niveis ou escalões de desenvolvimento profissional, muitas vezes relacionados à posse de novas competências profissionais, ao desenvolvimento de atividades mais complexas, à assunção de novas responsabilidades. No caso do PLC para os professores paulistas, esta complexidade funcional não está prevista na progressão da carreira, mas apenas a obtenção de determinadas pontuações em avaliação de conhecimentos específicos, cruzada com aspectos relacionados ao tempo de exercício na função, frequência e permanência no cargo. De qualquer forma, a promoção não se dá mais só pela antiguidade, mas também por critérios relacionados à formação e à prática profissional.

\section{Considerações finais}

O Projeto de Lei Complementar (PLC no 29/09) aqui analisado, ao instituir um sistema de promoção por mérito para os integrantes do magistério estadual paulista, inserese em quadro de iniciativas políticas da atualidade que relacionam processos externos de avaliação à remuneração dos profissionais da educação com o objetivo explícito de melhorar a qualidade de ensino; de tornar a carreira do magistério mais atrativa; de estimular o aperfeiçoamento individual dos professores; de melhorar a aprendizagem em decorrência de professores mais preparados e de gestão mais eficiente.

Essa iniciativa é apresentada como um marco importante no movimento de reestruturação das escolas paulistas, impondo à rede pública de ensino o mesmo tipo de pres- 
são competitiva que rege o funcionamento de empresas privadas. Nesse contexto, propicia-se - para não dizer fomenta-se - a disseminação de um tipo de pensamento, peculiar ao senso comum, que crê não haver nada de errado em melhorar a remuneração dos bons professores que desempenham trabalho mais eficiente. Além disso, a difusão dessa medida fundamenta-se no consenso de que modificar o pagamento dos professores é central para a melhoria da escola, tendo em vista a possibilidade de aumentar o status e a atratividade da carreira em relação a outras profissões.

Entretanto, parece que a questão central subjacente à qualidade da docência fica intocada, qual seja: a natureza complexa do trabalho do professor (e da escola). As medidas que associam explicitamente os diferenciais de salários ao desempenho profissional partem do suposto de que há uma relação imediata entre incentivos monetários e mudança de comportamento dos professores, desconsiderando resultados de vários estudos internacionais, como aqueles apresentados anteriormente. A grande dificuldade em identificar e medir o mérito do desempenho docente e relacioná-lo ao desempenho dos alunos tem sido decisiva para questionar e mesmo desestimular a utilização desses mecanismos de remuneração em vários países do mundo. Já foi apontado que os professores sentem-se mais estimulados pelos conteúdos e processos de seu trabalho que propriamente pelas oportunidades de ganho extra. Se a relação entre estímulo e resposta fosse imediata - isto é, se o pagamento por mérito de fato produzisse mudança no comportamento docente -, como querem crer tais iniciativas, os professores só desempenhariam bem se fossem recompensados, do contrário conteriam os seus esforços. 0 mesmo se pode dizer da tese que afirma que pagamentos uniformes desestimulam e provocam insatisfação nos melhores professores, fazendo com que deixem a sua profissão.

Essa tese tem por base a crença de que o incentivo financeiro é a mola mestra e determina o comportamento dos professores, desconsiderando fatores como o reconhecimento pessoal e profissional, o reconhecimento das ações e iniciativas individuais e coletivas; o aumento da responsabilidade dos profissionais pela confiança atribuída ao seu trabalho; a ascensão na carreira; os estímulos cotidianos advindos do próprio trabalho. Considerar esses fatores não significa afirmar que as recompensas monetárias e o reconhecimento social da profissão não cumprem um papel importante no recrutamento, na permanência e na assiduidade dos professores, ou mesmo no estímulo de individuos altamente qualificados para o ingresso na profissão. No entanto, recompensas monetárias não influenciam necessária e diretamente o nível de engajamento profissional.

De qualquer forma o PLC, ao estabelecer a meritocracia como critério para a promoção na carreira, ao que parece, não foi de fato concebido para motivar o desempenho docente, mas projetado para ser uma forma barata de aumentar a remuneração de poucos professores e deixar a massa salarial restante inalterada, uma vez que estabelece limite máximo de promoção de servidores em cada faixa, ainda 
que um número maior de profissionais venha a se sair bem no processo avaliativo. Em outras palavras, o PLC promove a competição entre os professores por fundos limitados, o que vai na contramão de uma cultura colaborativa existente na maior parte das escolas consideradas altamente eficientes e, portanto, estranha às estratégias que visam à melhoria da performance escolar. Além disso, vai também no sentido contrário ao que parece ser sua própria base de sustentação, já que, ao limitar o pagamento por mérito a uma parcela previamente fixada de professores de cada faixa, a iniciativa se mostra disfuncional, à medida que provocará desestímulo e desmotivação naqueles professores cujos resultados forem satisfatórios, mas não forem contemplados.

\section{Referências}

AGERRONDO, I. Os desafios da Política educacional relativos às reformas da formação docente. In: CONFERÊNCIA REGIONAL, 2002, Brasília. O desempenho dos professores na América Latina e no Caribe: novas prioridades. São Paulo: Fundação Victor Civita, 2004.

AZANHA, J M P. Uma reflexão sobre a formação do professor da escola básica. In: A formação do professor e outros escritos. SP: SENAC, 2006.

BOURDIEU, P. Contrafogos: táticas para enfrentar a invasão neoliberal. Tradução de Lucy Magalhães. Rio de Janeiro: Jorge Zahar, 1998.

BURGESS, S. et al. The intricacies of the relationship between pay and performance for teachers: do teachers respond to performance related pay schemes?. Bristol: University of Bristol, Centre for Market and Public Organisation, 2001. Disponível em: <http://www.bris.ac.uk/cmpo/publications/ papers/2001/wp35.pdf>. Acesso em: 30 mar. 2011.

CAMPANHA salarial 2009: contra o Projeto de Lei 29/09: proposta do governo é discriminatória. APEOESP, São Paulo, p. 1-4, ago. 2009. Boletim especial.

Disponivel em: <http://apeoespsub.org.br/camp_salarial_2009/ boletim_especial_agosto_2009.pdf>. Acesso em: 28 mar. 2011.

CAREAGA, A. Sintese de recomendações. In: CONFERÊNCIA REGIONAL, 2002, Brasilia. O desempenho dos professores na América Latina e no Caribe: novas prioridades. São Paulo: Fundação Victor Civita, 2004.

DARLING-HAMMOND, L. Teacher Quality and Student Achievement: a Review of State Policy Evidence. Educational Policy Analysis Archives, Tempe, AZ, v. 8, n. 1, Jan. 1, 2000. Disponivel em: <http://epaa.asu.edu/epaa/v8n1/>. Acesso em: 30 mar. 2011. 
EBERTS, R.; HOLLENBECK, K.; STONE, J. Teacher performance incentives and student outcomes. Journal of Human Resources, Madison, WI, v. 37, n. 4, 2000. Disponivel em: <http://www.upjohninstitute.org/publications/wp/00-65.pdfs. Acesso em: 30 mar. 2011.

FRANCO, C. Educação das elites no Brasil: a Bélgica não existe. Trabalho e Sociedade, Rio de Janeiro, ano 2, n. 4, p. 13-15, ago. 2002.

FREITAS, H. C. L. Formação de professores no Brasil: 10 anos de embate entre projetos de formação. Educação \&t Sociedade, Campinas, SP, v. 23, n. 80, p.137-168, 2002. GESOUI, L. C. Organização da escola, absenteísmo docente, discente e rendimento escolar. Dissertação (Mestrado em Educação: História, Política, Sociedade) - Pontifícia Universidade Católica, São Paulo, 2007.

JACOBSON, S. Performance related pay for teachers: the American experience. In: TOMLINSON, H. Performance related pay in education. London: Routledge, 1992. Disponivel em: < http://www.gse.buffalo.edu/Fas/Jacobson/629/ pdffiles/ b025329487.pdf>. Acesso em: 30 mar. 2011.

KELLEY, C.; ODDEN, A. Reinventing teacher compensation systems. CPRE Finance Briefs: reporting on issues and research in education finance, Philadelphia, PA, p. 1-11, 6 sept. 1995. Disponivel em: <http://www.cpre.org/ index.php?option=com_content\&task=view\&tid=166\&ttemid=121>. Acesso em: 20 mar. 2011.

MIZALA, A.; ROMAGUERA, P. O Sistema Nacional de Avaliação do Desempenho Docente (SNDE) no Chile. In: CONFERÊNCIA REGIONAL, 2002, Brasilia. 0 desempenho dos professores na América Latina e no Caribe: novas prioridades. São Paulo: Fundação Victor Civita, 2004.

RAMA, W. G.; NAVARRO, J. C. Carreira dos professores na América Latina. In: CONFERÊNCIA REGIONAL, 2002, Brasilia. O desempenho dos professores na América Latina e no Caribe: novas prioridades. São Paulo: Fundação Victor Civita, 2004.

REICHARDT, R. Toward a comprehensive approach to teacher quality. Midcontinent research for education and learning, Aurora, Colorado, p. 1-12, Nov. 2001. Disponivel em: <http://www.mcrel.org/PDF/PolicyBriefs/ 5012PI_PBTowardAComprehensive.pdf>. Acesso em: 30 mar. 2011.

SÃO PAULO (Estado). Decreto $\mathrm{n}^{\circ}$ 55.217, de 21 de dezembro de 2009. Regulamenta a Lei Complementar n ${ }^{0}$ 1.097, de 27 de outubro de 2009, que institui o sistema de promoção para os integrantes do Quadro do Magistério da Secretaria da Educação e dá outras providências. Diário Oficial do Estado de São Paulo, São Paulo, 22 dez. 2009a. 
SÃO PAULO (Estado). Lei Complementar nº. 836, de 30 de dezembro de 1997. Institui Plano de Carreira, vencimentos e salários para os integrantes do Quadro do Magistério da Secretaria da Educação. Diário Oficial do Estado de São Paulo, São Paulo, v. 107, n. 251, 31 dez. 1997.

. Lei Complementar no. 1.054, de 14 de abril de 2008. Dispõe sobre 0 vencimento, a remuneração ou o salário do servidor que deixar de comparecer ao expediente em virtude de consulta ou sessão de tratamento de saúde e dá providências correlatas. Diário Oficial do Estado de São Paulo, São Paulo, 15 abr. 2008. Disponivel em: <http://www.udemo.org.br/LC\%201041_08.htm>. Acesso em: 30 mar. 2011.

Lei Complementar $n^{\circ}$. 1.097, de 27 de outubro de 2009. Institui o sistema de promoção para os integrantes do Quadro do Magistério da Secretaria da Educação e dá outras providências. Diário Oficial do Estado de São Paulo, São Paulo, 28 out. 2009b. Seção 1, p. 1. Disponivel em: <http://www.jusbrasil.com.br/legislacao/819898/ lei-complementar-1097-09-sao-paulo-sp>. Acesso em: 28 mar. 2011.

SCHULMEYER, A. Estado atual da avaliação docente em treze paises da América Latina - Trabalho do Grupo de Interesse sobre Avaliação Docente. In: CONFERÊNCIA REGIONAL, 2002, Brasilia. O desempenho dos professores na América Latina e no Caribe: novas prioridades. São Paulo: Fundação Victor Civita, 2004.

VEGAS, E.; DE LAAT, J. Do differences in teacher contracts affect student performance?: evidence from Togo. Providence, 2003. Disponivel em: <http:// www-wds.worldbank.org/servlet/WDSContentServer/WDSP/IB/2003/10/24/ 000160016_20031024103517/additional/310436360_20050276095003.pdf>. Acesso em: 30 mar. 2011.

WRAGG, T. et al. Performance-related pay: the views and experiences of 1000 primary and secondary head teachers. Research Papers in Education, London, v. 18, n. 1, p. 3-23, Apr. 2003. Disponivel em: <http://eric.exeter.ac.uk/exeter/ handle/10036/47117>. Acesso em: 30 mar. 2011.

Recebido em: 09/12/2009

Aceito para Publicação em: 27/12/2010 